\title{
Association between prolonged use of smartphone and the incidence of dry eye among junior high school students
}

\author{
Marlyanti Nurrahmah Akib ${ }^{a, *}$, Suryana Rannu Pirade ${ }^{a}$, Siti Rukiah Syawal ${ }^{a}$, \\ Muhammad Miftah Fauzan ${ }^{\mathrm{b}}$, Hasnah Eka ${ }^{\mathrm{a}}$, Arifin Seweng ${ }^{\mathrm{c}}$ \\ ${ }^{a}$ Division of External Eye Disease and Pediatric Ophthalmology, Department of Ophthalmology, Faculty of Medicine, Universitas Hasanuddin, Indonesia \\ ${ }^{\mathrm{b}}$ English Department, Faculty of Language and Literature, Universitas Negeri Makassar, Indonesia \\ ${ }^{\mathrm{c}}$ Faculty of Medicine, Universitas Hasanuddin, Indonesia
}

\section{A R T I C L E I N F O}

\section{Keywords:}

Dry eye

Smartphone use

Dry eye in adolescents

\begin{abstract}
A B S T R A C T
This study aims to investigate the association between prolonged use of smartphone and the incidence of dry eye among adolescents. A cross sectional study was performed among junior high school students in Makassar. Of 143 students within the age of 12-16 years old, 74 were those with over 3-h use of smartphone, while 69 spent less than or equal to $3 \mathrm{~h}$. Ocular Surface Disease Index (OSDI) questionnaire was performed, followed by blink rate, Tear Break Up Time (TBUT), Tear Meniscus Height (TMH) examinations, and Schirmer test. Pearson's correlation, Independent-t and Chi Square tests were employed for data analysis. The result indicates that there was a significant association between the prolonged use of smartphone and dry eye incidence as specified by OSDI score ( $\mathrm{p}<0,01)$, abnormal blink rate ( $\mathrm{p}<0,01)$, TBUT $(\mathrm{p}<0,05)$, TMH ( $<<0,01)$, dan Schirmer test ( $<<$ 0,01). The more extent use of smartphone, the lower the scores of abnormal blink rate, TBUT, TMH, and Schirmer tests were obtained, and the higher OSDI score was gained. In conclusion, the prolonged use of smartphone promotes various eye disorders. Therefore, parental advisory upon the smartphone use among adolescents is necessary to prevent the detrimental effects.
\end{abstract}

\section{Introduction}

Seeing objects at close range is common in adults and children. Activities that tend to force individuals to see objects closely can be in the form of reading, doing schoolwork, and using a smartphone. A survey conducted by the ASEAN Parent Insights among 2714 parents in 5 Southeast Asian countries in 2014 reveals that $98 \%$ of children actively used smartphones; $67 \%$ used their parents', $18 \%$ had their other family members, and $14 \%$ used their own smartphones. In addition, $41 \%$ of them spent more than $1 \mathrm{~h}$ in a single moment of sitting, 37\% at 30-60 min, $21 \%$ at $1-30 \mathrm{~min}$, and only $2 \%$ without smartphone-related activity. ${ }^{1}$

Abnormal blink rate happens when children keep their eyes open to stay focus on the display, reducing the blink rate up to 5-6 times/minute. This condition increases the duration of exposure and evaporation on the ocular surface and can lead to instability of the tear layer, resulting in complaint of dry eye. ${ }^{2}$

Previous studies show that children with prolonged use of smartphones are usually prone to dry eyes. The activity where children maintain to stay focused on an object that they see on the screen results in a decrease of blinking frequency and causes a high rate of exposure to the ocular surface. This circumstance, in the long period of time, can lead to dry eye. Kabali also observed that children generally spend $2 \mathrm{~h}$ per day staring at the monitor screen. Furthermore, Parihar et all stated that the symptoms were mostly found in people who work with computers or smartphones for more than $4 \mathrm{~h}$ per day. ${ }^{3}$

Studies have shown that the presence of symptoms is sufficient to diagnose this disease because there is no specific examination for an absolute diagnosis of dry eye. However, symptoms cannot be the only indicator in the diagnosis of dry eye because of the possibility of abnormalities that may occur on the ocular surface and tears. Therefore, subjective and objective examinations are necessary. Other studies state that dry eye increases in old age and is rare in children because most of the factors involved in the pathophysiology of dry eye are more common in adults. ${ }^{4-6}$ This fact affects the number of researches, concerning the prevalence and characteristics of dry eye in children, which are still very

\footnotetext{
* Corresponding author. Perintis Kemerdekaan, Km 10. Tamalanrea, Makassar, Indonesia.

E-mail address: suryanara28@yahoo.com (M.N. Akib).
} 
limited. Another fact is that the ability of children to express discomfort in ocular surfaces is lower than that in adults.

This study aims to investigate the association between prolonged time in smartphone use and the incidence of dry eye in junior high school students.

\section{Method}

A cross sectional method was performed in this research along with an observational analysis to determine the association between prolonged use of smartphone and the incidence of dry eye among adolescents. The principle of Helsinki declaration was applied. The research was approved by the Health Research Ethics Committee of Hasanuddin University with the authorization number: 1110/H4.8.4.5.31/PP36KOMETIK/2018.

The study was conducted in 3 months at 4 junior high schools consisting of 2 Public Schools and 2 Islamic Boarding Schools in Makassar. The schools were randomly selected based on 2 categories: Public Schools and Islamic Boarding Schools at the secondary level. These schools were distinguished based on the rules of using communication media; Islamic boarding schools are dormitory-based institution where smartphone use is restricted, while public schools are general educational institution and do not apply the same school regulation upon smartphone use.

Proportional random sampling was performed to determine the research sample. Of 124 participants, 62 were the subjects, and the other 62 were the control group. Participants were within the age of 12-16 years, who met the inclusion criteria and were eligible to take part in the study. Exclusion criteria consisted of a history of eye surgery, palpebral anatomy abnormalities, nocturnal lagophthalmos, systemic disease, any use of soft lenses, and children with allergic conjunctivitis followed by a history of antihistamine medication.

The data were collected by conducting a personal interview and recording the complete identity of all research subjects to obtain information about the criteria using prepared questions. The questions consisted of a history of patients related to eye health ${ }^{1}$ : Whether the subject underwent surgery or medical treatment at the eye health clinic, followed by information about the results of the diagnosis. ${ }^{2}$ Whether the subject wears glasses or soft lenses on a daily basis. ${ }^{3}$ Whether there is a history of allergies with hypo-allergenic drug therapy, ${ }^{4}$ whether there is discomfort in the eyes with a verdict scale. ${ }^{5}$ Duration of smartphone usage in a day. The duration of using a smartphone is the amount of time a student spends over one day in units of hours, with a minimum period of 1 month.

Objective Criteria:

Normal (category without smartphone use): $\leq 3 \mathrm{~h}$ /day.

High (category with smartphone use): $>3 \mathrm{~h} /$ day.

The measurement of blink rate for 1-min during smartphone use was done observationally in the interview. This calculation process was performed three times. Normal blink rate ranged from 10 to 15 times/ minute.

Objective criteria:

Low: $\leq 10$ times/minute.

Normal: $>10-15$ times/minute.

High: $\geq 15$ times/minute.

After the interview process, participants filled out the modified OSDI (Ocular Surface Disease Index) questionnaire. This index was an objective parameter for the diagnosis of dry eye. Scoring was determined on a scale of 1-100 points, where the highest score indicated the presence of severe dry eye complaints.

Routine ophthalmological examinations were performed, starting from the anamnesis, visual examination with Snellen chart, and examination of the anterior segment of the eye by using a slit lamp biomicroscope. Next, the subjects underwent Tear Break-up Time (TBUT) examination with the following steps: applying a fluorescein strip (OptiGlo-Ophtechnics Unlimited) combined with 1 drop of
Table 1

Total samples based on the categories of school.

\begin{tabular}{llll}
\hline Schools & & $\mathrm{n}$ & $\%$ \\
\hline & SMPN 35 & 36 & 25,2 \\
& SMPN 13 & 38 & 26,6 \\
Darul Arqam & 29 & 20,3 \\
& IMMIM & 40 & 28,0 \\
Total & $\mathbf{1 4 3}$ & $\mathbf{1 0 0 , 0}$ \\
\hline
\end{tabular}

physiological fluid (balanced salt solution) (BSS; Alcon Laboratories, Inc., Fort Worth, TX) on the inferior conjunctival fornix of the eye. The subjects were asked to blink 3 times to spread the substance before asked to look straight ahead without blinking. LAM evaluation using a cobalt blue filter on the slit lamp and the time between the last blink and the onset of dry spot on the LAM was measured using a stopwatch. Interpretation: $>10$ s: normal, $6-10 \mathrm{~s}$ : mild dry eye, $\leq 5 \mathrm{~s}$ : severe dry eye.

Tear meniscus height (TMH) examination was performed using fluorescent strips in the inferior fornix conjunctival eye before observing thin fluid in the meniscus along the ocular surface and palpebral margo with the slit lamp. Objective criteria for TMH Dry Eye was $<0.3 \mathrm{~mm}$.

The subjects underwent the Schirmer Examination (Schirmer test). Schirmer strip paper was stored into the inferior conjunctival sac in the temporal third of the inferior palpebral on the right and left eye. The subjects were asked to keep their eyes to remain open before asked to blink. After $5 \mathrm{~min}$, the strip was removed, and the length of the wet filter paper was measured. Objective criteria: Normal: if the wetting length was $\geq 15 \mathrm{~mm}$ long, mild dry eye: $9-14 \mathrm{~mm}$, medium dry eye: $4-8 \mathrm{~mm}$, heavy dry eye $<4 \mathrm{~mm}$. Each ophthalmology examination was repeated up to 3 times to obtain the average value.

\subsection{Data analysis}

Data were analyzed through a computer program using statistical package for social science (SPSS) version 22. The statistical analysis conducted was descriptive statistical calculations and frequency distribution, followed by Pearson's Correlation statistical tests, Independent-t and Chi Square tests. The correlation was significant if the $\mathrm{p}$ value remained $<0.05$.

Table 2

Characteristics of variables $(n=143)$.

\begin{tabular}{|c|c|c|c|}
\hline \multicolumn{2}{|l|}{ Variables } & \multirow{2}{*}{$\frac{N}{65}$} & \multirow{2}{*}{$\frac{\%}{45,5}$} \\
\hline Gender & Male & & \\
\hline & Female & 78 & 54,5 \\
\hline \multirow[t]{3}{*}{ Blink Rate } & Low $(\leq 10)$ & 66 & 46,2 \\
\hline & Normal $^{10-15}$ & 77 & 53,8 \\
\hline & High $(\geq 10)$ & 0 & 0 \\
\hline \multirow[t]{3}{*}{ TBUT } & Heavy DE $(\leq 5 \mathrm{~s})$ & 0 & 0 \\
\hline & Mild DE (6-10 s) & 32 & 22,4 \\
\hline & Normal $(>10 s)$ & 111 & 77,6 \\
\hline \multirow[t]{2}{*}{ TMH } & Dry Eye $(<0,3 \mathrm{~mm})$ & 25 & 17,5 \\
\hline & Normal $(\geq 0,3 \mathrm{~mm})$ & 118 & 82,5 \\
\hline \multirow[t]{4}{*}{ Schirmer } & Heavy DE $(<4 \mathrm{~mm})$ & 0 & 0 \\
\hline & Medium DE (4-8 mm) & 0 & 0 \\
\hline & Mild DE (9-14 mm) & 42 & 29,4 \\
\hline & Normal $(\geq 15 \mathrm{~mm})$ & 101 & 70,6 \\
\hline \multirow[t]{4}{*}{ OSDI } & Heavy DE (33-100) & 6 & 4,2 \\
\hline & Medium DE (23-32) & 26 & 18,2 \\
\hline & Mild DE (13-22) & 39 & 27,3 \\
\hline & Normal (0-12) & 72 & 50,3 \\
\hline \multirow[t]{2}{*}{ Smartphone Use Duration } & $>3 \mathrm{~h}$ & 74 & 51,7 \\
\hline & $<3$ jours & 69 & 48,3 \\
\hline
\end{tabular}

aDE: Dry Eye. 
Table 3

The Statistics of the research variables $(n=143)$.

\begin{tabular}{lllll}
\hline Variables & Minimum & Maximum & Mean & SD \\
\hline Blink Rate & 6 & 14 & 9,08 & 1,70 \\
TBUT & 6 & 21 & 13,13 & 3,46 \\
TMH & 0,2 & 0,5 & 0,31 & 0,07 \\
Schirmer & 10 & 18 & 14,57 & 1,82 \\
OSDI & 0,0 & 50,0 & 17,35 & 10,97 \\
Smartphone Use Duration (hours) & 1 & 16 & 4,54 & 3,89 \\
\hline
\end{tabular}

Table 4

Dry eye test and the duration of smartphone use.

\begin{tabular}{lll}
\hline Variables & Duration & \\
\cline { 2 - 3 } & Coefficient Correlation & \\
& a & $\mathrm{P}$ \\
\hline Blink Rate & $-0,297$ & 0000 \\
TBUT & $-0,244$ & 0003 \\
TMH & $-0,379$ & 0000 \\
Schirmer & $-0,324$ & 0000 \\
OSDI & 0,440 & 0000 \\
\hline
\end{tabular}

Pearson's Correlation, Independent-t, and chi square test.

a Negative Value of Coefficient Correlation shows negative correlation.

\section{Results}

\subsection{Characteristics of the samples}

A cross sectional analytic study was conducted to assess the relationship between the prolonged use of smartphone and the incidence of dry eye among junior high school students in children aged 12-16 years with the mean of $12.7 \pm 0.8$ years. There were 143 participants, consisting of 36 students from SMPN 35 Makassar, 38 students from SMPN 13 Makassar, 29 students from Darul Arqam Gombara Islamic Boarding School, and 40 students from the Makassar IMMIM Islamic Boarding School (Table 1), randomly selected and based on the inclusion criteria.

Research subjects were grouped into two: the first group were those with a smartphone usage duration of less than or equal to $3 \mathrm{~h}$, and the second group were those with a smartphone usage duration of more than $3 \mathrm{~h} 74$ subjects were included in the first group, and 69 subjects were in the second group. All subjects received the same treatment and examination.

Based on the research variables, the results of the study showed that most of the subjects studied were women (54.5\%). The examination results showed that there was only mild dry eye in the sample of junior high school students (Table 2).

Based on the descriptive variable statistics, the blink rate ranges from 6 to 14 with an average of $9.1 \pm 1.7$. This result shows that the lowest sample blink rate is 6 times per minute and the highest is 14 times per minute (Table 3).

The test results showed a significant negative correlation between the duration of smartphone usage and blink rate, TBUT, TMH, and Schirmer. Data indicate that the longer duration of smartphone usage shows the smaller blink rate, TBUT, TMH and Schirmer values $(\mathrm{p}<$ 0.01 ). Meanwhile, there is a significant positive correlation between the duration of smartphone use and the OSDI value. Smartphone usage in a long duration shows an increasingly greater OSDI value $(p<0.001)$ (Table 4).

\subsection{Analysis of dry eye test}

The result of the dry eye test showed a significantly smaller blink rate in the category of smartphone usage duration of $>3 \mathrm{~h}$ compared to that of normal duration, ie 8.55 and 9.64 respectively $(\mathrm{p}<0.001)$. Based on the TBUT value, there was no significant difference between the category of smartphone duration for $>3 \mathrm{~h}$ and that of normal duration with
Table 5

The Analysis of Dry Eye Test based on the Duration of Smartphone Usage.

\begin{tabular}{llllll}
\hline Variables & Duration of Use (hours) & $\mathrm{n}$ & Mean & $\mathrm{SD}$ & $\mathrm{P}$ \\
\hline \multirow{2}{*}{ Blink Rate } & $>3$ & 74 & 8,55 & 1,69 & 0,000 \\
\multirow{2}{*}{ TBUT } & $<3$ & 69 & 9,64 & 1,53 & \\
& $>3$ & 74 & 12,88 & 3,93 & 0,364 \\
TMH & $<3$ & 69 & 13,41 & 2,87 & \\
& $>3$ & 74 & 0,29 & 0,07 & 0,000 \\
\multirow{2}{*}{ Schirmer } & $>3$ & 69 & 0,33 & 0,06 & \\
\multirow{2}{*}{ OSDI } & $>3$ & 74 & 14,03 & 2,14 & 0,000 \\
& $>3$ & 69 & 15,16 & 1,15 & \\
& $<3$ & 74 & 20,48 & 12,30 & 0,000 \\
\hline
\end{tabular}

Pearson's Correlation, Independent-t dan chi square test.

Table 6

The relationship of the duration of smartphone use and blink rate.

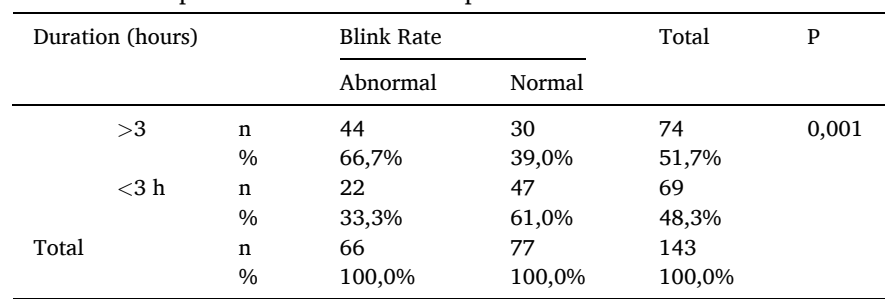

Pearson's Correlation, Independent-t dan chi square test.

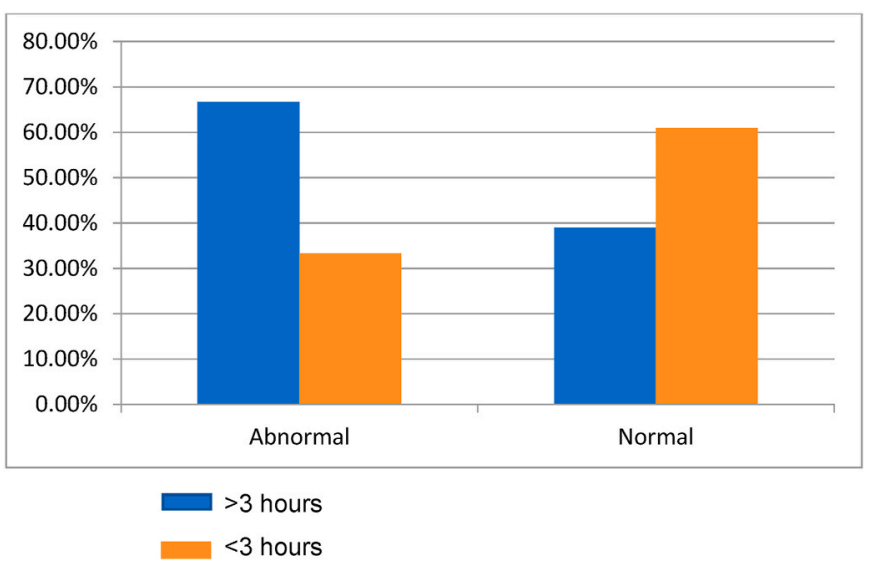

Fig. 1. The relationship of the duration of smartphone use and blink rate.

12.88 and 13.41 respectively ( $\mathrm{p}>0.05$ ). On $\mathrm{TMH}$, the value in the category of smartphone usage duration at $>3 \mathrm{~h}$ was significantly smaller than the category of normal duration with 0.29 and 0.33 (p $<0.001$ ). Meanwhile, the value in the category of smartphone usage duration at $>3 \mathrm{~h}$ was significantly smaller than the normal duration category with 14.03 and 15.16 ( $p<0.001)$. On the examination of the OSDI questionnaire, the value in the category of smartphone use duration at $>3 \mathrm{~h}$ was significantly greater than the normal duration category with 20.48 and 14.00 respectively $(\mathrm{p}<0.001)$ (Table 5$)$.

\subsection{The analysis on the proportion of dry eye}

The results of the examination of dry eye parameters among the subjects illustrated the relationship of the duration of smartphone use and dry eye. Table 6 and Fig. 1 below show the comparison of the proportions of each dry eye examination parameter.

Table 6 and Fig. 1 show the proportion of abnormal blink rate (less than 10 times per minute). It can be seen that the rate in the duration of smartphone usage with $>3 \mathrm{~h}$ was significantly higher $(66.7 \%)$ than that of $\leq 3 \mathrm{~h}(33.3 \%)$. These results indicate a significant relationship 
Table 7

The duration of smartphone use and dry eye (TBUT).

\begin{tabular}{|c|c|c|c|c|c|c|}
\hline \multicolumn{3}{|c|}{ Duration (hours) } & \multicolumn{2}{|l|}{ TBUT } & \multirow[t]{2}{*}{ Total } & \multirow[t]{2}{*}{$\mathrm{p}$} \\
\hline & & & Mild DE & Normal & & \\
\hline \multirow{2}{*}{\multicolumn{2}{|c|}{$>3$}} & $\mathrm{n}$ & 27 & 47 & 74 & \multirow[t]{6}{*}{0,000} \\
\hline & & $\%$ & $84,4 \%$ & $42,3 \%$ & $51,7 \%$ & \\
\hline \multirow{4}{*}{ Total } & \multirow[t]{2}{*}{$<3$} & $\mathrm{n}$ & 5 & 64 & 69 & \\
\hline & & $\%$ & $15,6 \%$ & $57,7 \%$ & $48,3 \%$ & \\
\hline & & $\mathrm{n}$ & 32 & 111 & 143 & \\
\hline & & $\%$ & $100,0 \%$ & $100,0 \%$ & $100,0 \%$ & \\
\hline
\end{tabular}

TBUT: Tear Break Up Time.

Pearson's Correlation, Independent-t dan chi square test.

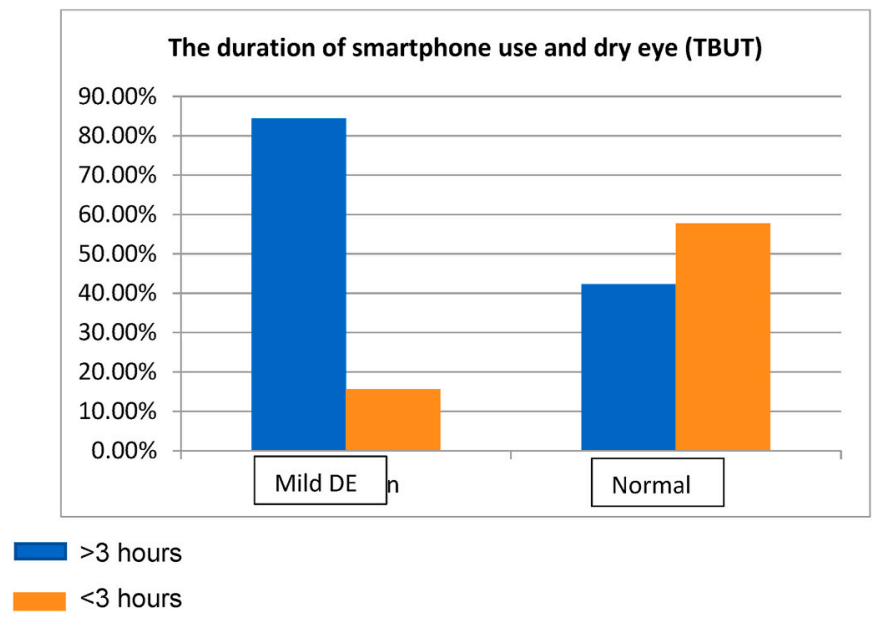

Fig. 2. The duration of smartphone use and dry eye (TBUT).

Table 8

The duration of smartphone use and dry eye (TMH).

\begin{tabular}{|c|c|c|c|c|c|c|}
\hline \multicolumn{3}{|c|}{ Duration (hours) } & \multicolumn{2}{|l|}{ TMH } & \multirow[t]{2}{*}{ Total } & \multirow[t]{2}{*}{$\mathrm{p}$} \\
\hline & & & Dry Eye & Normal & & \\
\hline & \multirow[t]{2}{*}{$>3$} & $\mathrm{~N}$ & 23 & 51 & 74 & \multirow[t]{2}{*}{0,000} \\
\hline & & $\%$ & $92,0 \%$ & $43,2 \%$ & $51,7 \%$ & \\
\hline & \multirow[t]{2}{*}{$<3$} & $\mathrm{~N}$ & 2 & 67 & 69 & \\
\hline & & $\%$ & $8,0 \%$ & $56,8 \%$ & $48,3 \%$ & \\
\hline \multirow[t]{2}{*}{ Total } & & $\mathrm{N}$ & 25 & 118 & 143 & \\
\hline & & $\%$ & $100,0 \%$ & $100,0 \%$ & $100,0 \%$ & \\
\hline
\end{tabular}

TMH: Tear Meniscus Height.

Pearson's Correlation, Independent-t dan chi square test.

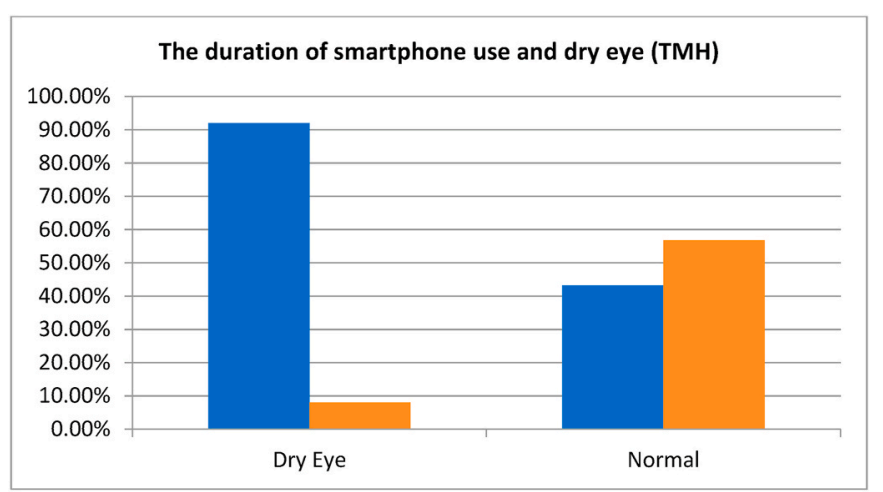

$>3$ hours

$<3$ hours

Fig. 3. The duration of smartphone use and dry eye (TMH).
Table 9

The duration of smartphone use and dry eye (Schrimer Test).

\begin{tabular}{|c|c|c|c|c|c|c|}
\hline \multicolumn{3}{|c|}{ Duration (hours) } & \multicolumn{2}{|l|}{ Schirmer } & \multirow[t]{2}{*}{ Total } & \multirow[t]{2}{*}{$\mathrm{p}$} \\
\hline & & & Mild DE & Normal & & \\
\hline \multirow{2}{*}{\multicolumn{2}{|c|}{$>3$}} & $\mathrm{n}$ & 33 & 41 & 74 & \multirow[t]{6}{*}{0,000} \\
\hline & & $\%$ & $78,6 \%$ & $40,6 \%$ & $51,7 \%$ & \\
\hline \multirow{4}{*}{ Total } & \multirow[t]{2}{*}{$<3$} & $\mathrm{n}$ & 9 & 60 & 69 & \\
\hline & & $\%$ & $21,4 \%$ & $59,4 \%$ & $48,3 \%$ & \\
\hline & & $\mathrm{n}$ & 42 & 101 & 143 & \\
\hline & & $\%$ & $100,0 \%$ & $100,0 \%$ & $100,0 \%$ & \\
\hline
\end{tabular}

Pearson's Correlation, Independent-t dan chi square test. ${ }^{\mathrm{a} D E}$ : Dry Eye.

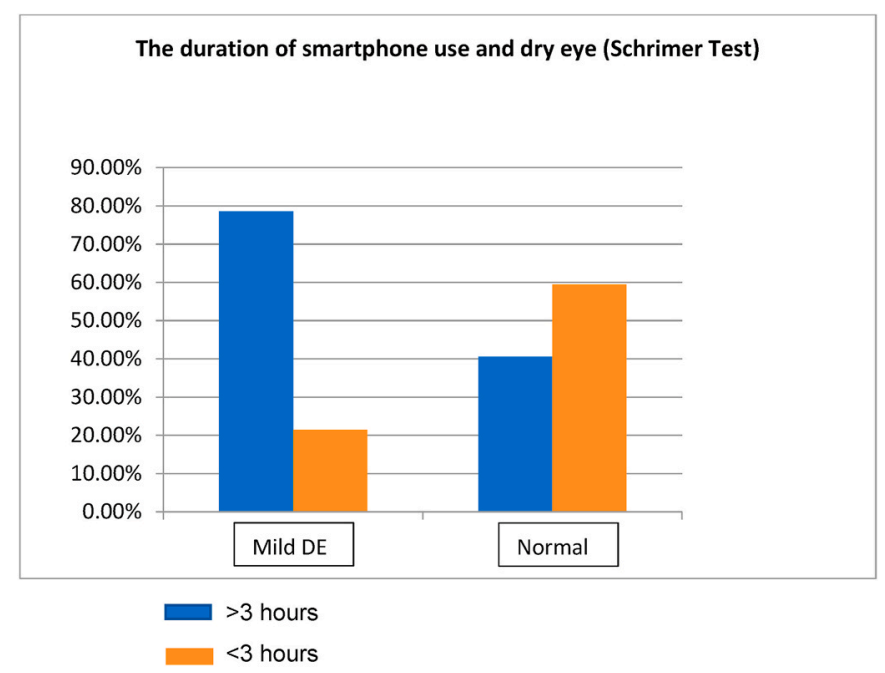

Fig. 4. The duration of smartphone use and dry eye (Schrimer Test).

between the prolonged use of smartphone and abnormal blink rate ( $\mathrm{p}<$ $0.01)$.

Table 7 and Fig. 2 show that the proportion of mild dry eye in the group with the duration of smartphone use with $>3 \mathrm{~h}(84.4 \%)$ was significantly higher than the group of smartphone usage with $\leq 3 \mathrm{~h}$ (15.6\%). These results indicated a significant association between prolonged use of smartphone and mild dry eye $(\mathrm{p}<0.001)$.

Table 8 and Fig. 3 show that the proportion of mild dry eye in the group with the duration of smartphone use with $>3 \mathrm{~h}(92.0 \%)$ was significantly higher than the group of normal smartphone usage duration (8.0\%). These results indicated a significant association between prolonged use of smartphone and dry eye $(\mathrm{p}<0.001)$.

Table 9 and Fig. 4 show that the proportion of mild dry eye in the group with the duration of smartphone use with $>3 \mathrm{~h}(78.6 \%)$ was significantly higher than the group of normal smartphone usage duration (21.4\%). These results indicated a significant association between prolonged use of smartphone and dry eye $(p<0.001)$.

Table 10 and Fig. 5 show that the proportion of mild dry eye in the group with the duration of smartphone use with $>3 \mathrm{~h}$ was significantly higher than the group of smartphone usage with $\leq 3 \mathrm{~h}$. These results indicated a significant association between prolonged use of smartphone and dry eye $(\mathrm{p}<0.001)$.

\section{Discussion}

This study shows that there is a significant relationship between the duration of smartphone use and dry eye. Examination of OSDI scores showed a value of $\mathrm{p}<0.01$, abnormal blink rate with $\mathrm{p}<0.01$, TBUT with $\mathrm{p}<0.05$, TMH with $\mathrm{p}<0.01$, and Schirmer with $\mathrm{p}<0.01$. The prolonged use of smartphones indicated smaller value on the blink rate, TBUT, TMH and Schirmer. However, it showed greater value on the 
Table 10

The duration of smartphone use and dry eye (OSDI).

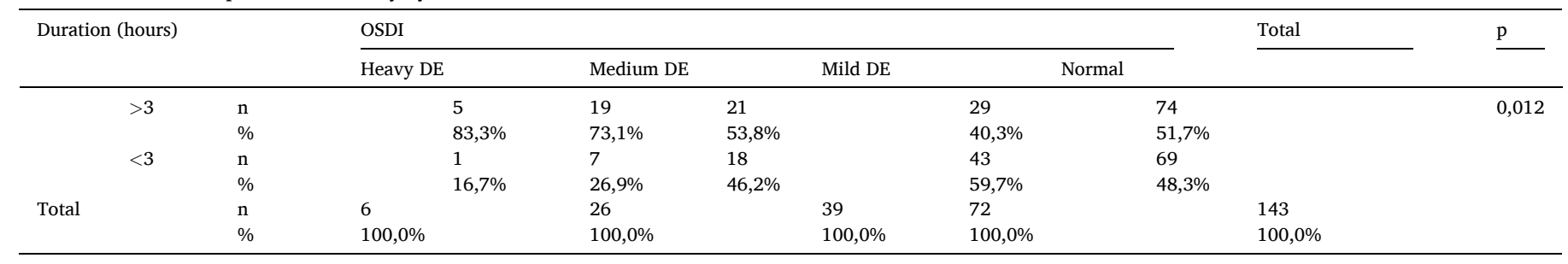

OSDI: Ocular Surace Disease Index.

Pearson's Correlation, Independent-t dan chi square test.

${ }^{\mathrm{a}} \mathrm{DE}=$ Dry Eye.

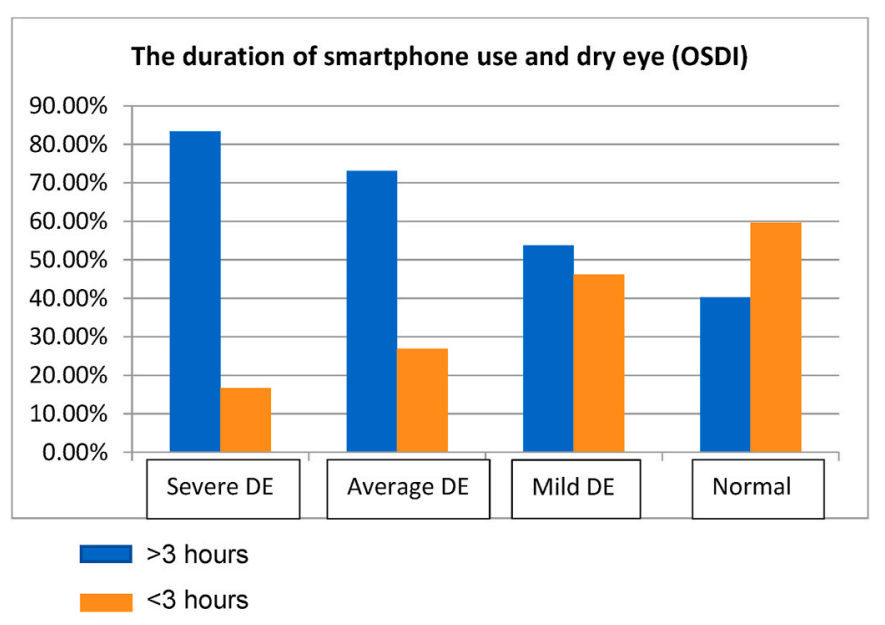

Fig. 5. The duration of smartphone use and dry eye (OSDI).

OSDI score.

The results of this study show the incidence of mild dry eye without moderate or severe level. The fact is likely influenced by the condition of the tear layer of children, which is better than that of adults. In addition, tear film stability in children is also better compared to adults, although there is no clear difference in tear secretion and other ocular surface variables. Some studies reveal that the prevalence of dry eye increases along with the age. It is caused by the degeneration process of the body, including the surface of the lacrimal system which can trigger dry eyes. $^{6-8}$

According to the test results, this study shows that there are several parameters with quite a different level of difference, such as OSDI questionnaire results, TBUT, and duration of smartphone usage. The diversity was likely influenced by differences in the activities and habits of each child, causing subjective and fluctuating complaints. The tables reveal the results of the analysis which shows a significant negative correlation between the prolonged use of smartphone and blink rate, as well as its correlation with dry eye based on TBUT, TMH and Schirmer.

The study shows that long duration of smartphone usage indicates the small blink rate, TBUT, TMH and Schirmer values $(\mathrm{p}<0.01)$. These results also indicate that the risk of dry eye can be higher in children with the prolonged use of smartphone. In addition, there is also a significant positive correlation between the long duration of smartphone use with the OSDI value with subjective complaints by the sample regarding the perceived dry eye. This parameter shows that the prolonged use of smartphone leads to the greater OSDI value $(\mathrm{p}<0.001)$. The data on Table 10 is similar to the result of study by Uchino et al. in Japan, reporting that dry eye complaints increased in office workers with the prolonged use of video display terminals. ${ }^{5}$

The results of the analysis in this study showed that smartphone usage for more than $3 \mathrm{~h}$ significantly affected the results on the measurement of blink rate, TMH, Schirmer, and OSDI and triggered dry eye. One of the factors contributing to teenagers' habits of using smartphones is the rapid development of internet and technology. ${ }^{10}$ In Indonesia, children frequently use terminal video displays such as smartphones or computers to view media content and the internet for a relatively long period of time. Various studies also reveal that the level of smartphone usage has increased enormously, especially among teenagers and school children. ${ }^{9,11,17,19}$

This study shows that there was a significant correlation between the prolonged use of smartphone and abnormal blink rate (Table 6). Several previous studies have reported that the use of a smartphone or computer can lead to evaporation of the tear layer due to a decrease in the number of blinks and imperfect blinks and (the eyes do not close completely when blinking). Research conducted by Inomata $\mathrm{T}$ et al., in 2018 states that the maximum blink interval at $\geq 12.4 \mathrm{~s}$ can cause dry eye. This indicates that there should be more than 5 perfect blinks within 1 min 14 . Likewise, research conducted by Wang (2018) states that imperfect blinking and a lack of blinking can be associated with a twofold increased risk of dry eye. ${ }^{12-15}$ The higher the dropout rate of meibomian glands is, the poorer meibomian quality and thickness of the tear layer, indicating that incomplete blinking and less blinking may predispose to dry eye evaporation. ${ }^{16}$ Portello et al. reported a positive correlation between incomplete blinking and dry eye symptoms in individual computer users. They found a negative correlation between the number of blinks and the same symptoms. ${ }^{20,21}$

The results of measurements with TBUT in this study showed a number of samples that experienced mild dry eye (Table 7). Mild dry eye is caused by prolonged ocular surface exposure resulting in greater evaporation and mild dry eye in children. This effect is probably caused by the condition of the biophysical meibomian glands and a thicker lipid layer in the tear layer of children than adults. ${ }^{18,22}$ According to the measurements on TBUT, the results of this study support the findings that prolonged use of smartphone results in the decreased tear stability.

\section{Conclusion}

This study has shown that there is a significant relationship between the prolonged use of smartphone and the incidence of dry eye. Smartphone usage of more than $3 \mathrm{~h}$ per day within 1 month can cause various eye complaints. Preventive program and education are needed to avoid the negative impact. In addition, It is also necessary to limit the duration of smartphone usage for both children and parents to prevent eye disorders.

\section{References}

1 Unantenne N. Mobile device usage among young kids A Southeast Asia study. Singapura; 2014.

2 Patong R. Hubungan Durasi Aktivitas Melihat Dekat Terhadap Amplitudo Fusi Dan Ketajaman Stereopsis Pada Anak. Makassar:Tesis Program Pascasarjana Fakultas Kedokteran Universitas Hasanuddin. 2018. 
3 Moon J, et al. Smartphone Use Is a Risk Factor for Pediatric Dry Eye Disease According to Region and Age: A Case Control Study. Seoul, Korea: Department of Ophthalmology, College of Medicine, Chung Ang University Hospital; 2016.

4 Alves M, Dias AC, Rocha EM. Dry eye in childhood: epidemiological and clinical aspects. Ocul Surf. 2008;6:44-51.

5 Uchino M, Schaumberg DA, Dogru M, et al. Prevalence of dry eye disease among Japanese visual display terminal users. Ophthalmology. 2008;115:1982-1988. 10.

6 Chidi N, et al. The Ocular Surface in Children: A Review of Current Knowledge and Metaanalysis of Tear Film Stability and Tear Secretion in Children. UNSW Sydney; 2018.

7 Gipson IK. Age-Related Changes and Diseases of the Ocular Surface and Cornea. Boston, Massachusetts: Harvard Cornea Center of Excellence, Schepens Eye Research Institute of Massachusetts Eye and Ear, and Department of Ophthalmology, Harvard Medical School; 2013.

8 Han SB, et al. Children with Dry Eye Type Conditions May Report Less Severe Symptoms than Adult Patients. Seoul: National University College of Medicine, Seoul National University Bundang Hospital. Korea; 2012. Department of Ophthalmology.

9 Sangkereng N, Syawal SR, Sirajuddin J. Profil lapisan air mata dan sitologi impressi pada diabetes mellitus type 2 , makassar:tesis program pascasarjana fakultas kedokteran universitas Hasanuddin. 2011.

10 Lee AJ, Lee J, Saw SM, et al. Prevalence and risk factor associated with dry eye symptom:A population based study in Indonesia:A population based study in Indonesia. Br J Ophtamol. 2002;86(12):1247-1351.

11 Kabali H MD, Irigoyen M MD, Davis R, Do MPH. Exposure and Use of Mobile Medid Devices by Young Children. Philadelphia: Department of Pediatric and Adolescent Medicine, Einstein Medical Center Philadelphia, Old York Road; 2015.

12 Phadatare S, Momin M, Nighojkar P, Review Article. A comprehensive review on dry eye disease: diagnosis, medical management, recent developments, and future challenges. Hindawi Publishing Corporation Advances in Pharmaceutics. 2015; ume.
13 Moon J, et al. Association between Video Display Terminal Use and Dry Eye Disease in School Children. Seoul, Korea: Department of Ophthalmology, College of Medicine Chung Ang University Hospital; 2014.

14 Nakamori K, Odawara m, Nakajima M. Blinking Is Controlled Primarily by Ocular Surface Conditions. saitama. Japan: Research Center of Taisho Pharmaceutical co ltd; 1997.

15 Freudenthaler N, et al. Characteristics of Spontaneous Eyeblink Activity during Video Display Terminal Use in Healthy Volunteers. Germany: Department of Youth Psychiatry; 2003.

16 Hirota M. Effect of Incomplete Blinking on Tear Film Stability. Kanagawa, Japan: Department of Visual Science, Kitasato University and Department of Ophthalmology, Fuchinobe General Hospital; 2013.

17 Kusumawaty S, Syawal R. Computer vision syndrome. Makassar: Tesis Program Pascasarjana Fakultas Kedokteran Universitas Hasanuddin. 2012.

18 The definition and classification of dry eye disease: report of the definition and classification subcommittee of the international dry eye WorkShop. Ocul Surf. 2007. 2007;5:75-92.

19 Syawal R. Suatu cakrawala baru mengenai pathogenesis dan penanganan sindrom dry eye. J.Medika Nusantara. 2005;26:84-87.

20 Patel S, Blades JK. The Dry Eye Apractical Approach. ButterWorth-Heinemann; 2003: 27-56.

21 Yoshimura M. et. al. Smartphone viewing distance and sleep: an experimental study utilizing motion capture technology. Nat Sci Sleep, March. 2017.

22 Hasegawa S, et al. Readability of characters on mobile phone liquid crystal displays. Int J Occup Saf Ergon. 2008 (School of Information Culture, Nagoya Bunri University. Japan). 